\title{
Brazilian Journal of Allergy and Immunology: on its way to internationalization
}

\author{
L. Karla Arruda, MD, PhD1
}

It's with great pleasure that I present to you the first issue of the Brazilian Journal of Allergy and Immunology - BJAI. Many of you, especially those who followed the publication of the "Revista Brasileira de Alergia e Imunopatologia" over the years, since 1979, with its 35 volumes, may feel uncomfortable with the changes, including the English name of the Journal and its new logotype.

BJAl represents the continuity of the "Revista Brasileira de Alergia e Imunopatologia", and arises with a solid foundation, thanks to the constructive work of the pioneer Editors, including Lain Pontes de Carvalho, Wilson Tartuce Aun, Charles Naspitz ${ }^{1}$ and Nelson Mendes. I would like to highlight the untiring and innovative work of Dirceu Solé, ${ }^{2}$ Editor of our Journal for 14 years (from 1993 to 2008), in partnership with Maria de Fátima Marcelos Fernandes during the periods of 1993/1994 and 1997/1998, and more recently, the work of Gustavo Wandalsen during the last 4 years, ${ }^{3}$ bringing reformulations that have been essential for the success of our Journal. To all of them, we owe gratitude and appreciation.

Even though the official journal of our Brazilian Association of Allergy and Immunopathology - ASBAI has a new look, its focus and objectives remain the same. The priority is to provide high quality scientific and professional information to physicians who practice the Allergy and Immunology specialty and to health professionals who work in related areas. Another aim is to spread and share results of innovative studies conducted in our country, including clinical and experimental studies, in order to increase knowledge, and consequently improve our daily clinical practice to excellence in patient's care.

However, we would like to move forward and promote more public awareness and visibility of our Association. One of the most appropriate strategies to achieve this goal is the internationalization of our Journal, however, being published in the Portuguese language limits this process. We've opted to initiate the transition by changing the name of the Journal to English as a first step, and by gradually making its content available on line in both languages, without modifying the printed form, which remains in Portuguese. In this progression to a better visibility of our Journal, as the scientific representative of our Association, a critical initial step is to expand its indexation to other data bases besides Lilacs, including SciELO and PubMed. In a very sincere and appropriate manner, Gustavo Wandalsen has pointed to the challenges involved in reaching these goals, in a recent Editorial ${ }^{3}$.

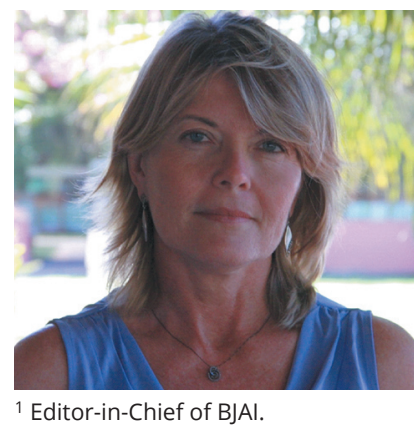

The priority is to provide high quality scientific and professional information to physicians who practice the Allergy and Immunology specialty and to health professionals who work in related areas.

Correspondence: Luisa Karla Arruda karla@fmrp.usp.br 
Over time, Brazilian Allergists and Immunologists have contributed a great deal to the world' sscience, being of particular interest the appreciation of peculiarities and unique aspects of our patients, sometimes revealing marked differences when compared to those living in more affluent countries. Together with the Associated Editors Antônio Condino Neto, Beatriz Tavares Costa Carvalho, Cristina Miuki Abe Jacob, Emanuel Sarinho, Mario Geller, the International Associated Editors Fátima Ferreira-Briza and Tari Haahtela, and the members of the Editorial Board of BJAI, I invite everyone to take part in this adventure/challenge by contributing with articles to our Journal. We trust that in a short period of time we will have a profile of publications that may allow expansion of BJAl indexing, maintaining the commitment with the principles of education of our specialists, as a contribution of each of us to our Association and to our country.

\section{REFERENCES}

1. Naspitz CK. A luta por uma nova imagem. Rev bras alerg imunopatol. 1987;10:4.

2. Solé D. A nova Revista Brasileira de Alergia e Imunopatologia. Rev bras alerg imunopatol. 2005;28:1.

3. Wandalsen GF. A Revista Brasileira de Alergia e Imunopatologia de 2009 a 2012: balanço e considerações. Rev bras alerg imunopatol. 2012;35:199-200. 